\title{
Residual stress redistribution during elastic shake down in welded plates
}

\author{
Jazeel R. Chukkan ${ }^{1,2, *}$, Guiyi $\mathrm{Wu}^{3}$, Michael E. Fitzpatrick ${ }^{1}$, Elvin Eren $^{3}$, Xiang Zhang ${ }^{1}$, and Joe Kelleher ${ }^{4}$ \\ ${ }^{1}$ Coventry University, Faculty of Engineering, Environment and Computing, Priory Street, Coventry, UK \\ ${ }^{2}$ NSIRC, TWI Ltd, Granta Park, Great Abington, Cambridge, CB21 6AL, UK \\ ${ }^{3}$ TWI Ltd, Granta Park, Great Abington, Cambridge, CB21 6AL, UK \\ ${ }^{4}$ ISIS Pulsed Neutron \& Muon Source, Harwell Campus, Didcot, Oxfordshire, UK
}

\begin{abstract}
Residual stresses are a consequence of welding in various structures such as ships and offshore structures. Residual stresses can be relaxed or redistributed according to the load levels during operation. The elastic shakedown phenomenon can be considered as one of the reasons for this change. This paper studies the relaxation/redistribution of weld residual stress during different levels of shakedown in a butt-welded plate chosen according to ship design and welding procedures. Welding was performed on DH36, a ship structural steel. Neutron diffraction was used to measure residual stresses in these plates in the as-welded state and after different levels of shakedown. A mixed hardening model in line with the Chaboche model is determined for both weld and base material. A numerical model is developed to estimate the shakedown limit on butt-welded plate. Further, the redistribution of residual stress in a numerical weld model according to the different levels of shakedown limit is studied. Based on the shakedown limit of the butt-welded plate, a shakedown region is determined, where the structure will undergo elastic shakedown in the presence of an existing residual stress field if the maximum stress on the load section after a few initial cycles is in the shakedown region.
\end{abstract}

\section{Introduction}

Welding is the primary joining technique used in many offshore structures which results induces in complex residual stresses in many components. Residual stresses in welded structures which are exposed to complex cyclic loads are sometimes observed to be different from the as-welded state [1]. One of the main reasons for this change is elastic shakedown. Elastic shakedown is defined as a plastic deformation causing a change in plasticity induced residual stress during the first few load cycles, followed by an elastic response which is associated with a limit called the shakedown limit [2]. On a structure, a primary load above the shakedown limit will result in reverse plasticity or ratchetting [3]. Generally, for a rigid-perfectly-plastic solid the load limit can be determined by using Melan's lower bound and Koiter's upper bound theorems [4,5]. These theorems in their original form assume linear kinematics and elastic-perfectly plastic material. However, linear or nonlinear isotropic and linear kinematic classics are two ideal models that are not representative for realistic structural materials subjected to cyclic loadings [6]. It is recommended to adopt analysis with mixed hardening models such as Chaboche [6, 7].

There has been much research on the shakedown analysis of components under thermal loads which are associated with a residual stress field following initial plastic deformation [3, 8]. However, little research is available on the shakedown analysis of components with a pre-existing weld residual stress field. These problems are generally considered as a stress relaxation or stress redistribution problem [9]. One of the reasons could be that in the presence of a residual stress field, elastic shakedown can result in relaxation or redistribution of the existing residual stress. However, shakedown analysis on these components could be used for understanding the effect of relaxation or redistribution of residual stresses on the state of elastic shakedown. It is worth noting that shakedown investigation has been used for predicting thresholds of a cracked body [10]. Also, the shakedown analysis of a ring-stiffened cylinder model was used to study variation in the ultimate strength of the component [11]. The shakedown limit on a welded plate is determined by considering absorbed plastic deformation energy as shakedown criterion [12].

Plastic deformation redistributes residual stresses thereby changing the pattern to achieve internal equilibrium. A welded structure can be subjected to a variety of loading during operation such as tensile, compression or alternating loading. In this study, the redistribution of residual stresses following different numbers of tensile load cycles were investigated.

\section{Governing equations}

\subsection{Constitutive model}

The numerical modelling is established on an elastic-plastic model initially developed by Lemaitre and Chaboche [7]. The model is implemented with a combination of one isotropic hardening $R$ and three kinematic hardenings $\alpha_{1}, \alpha_{2}$ and $\alpha_{3}$. Total strains $\varepsilon_{i j}^{t}$ are decomposed into elastic strains $\varepsilon_{i j}^{e}$ and plastic strains $\varepsilon_{i j}^{p}$.

Corresponding author: chukkanj@uni.coventry.ac.uk 
Table 1:Constitutive model parameters for DH36 steel in the FE model.

\begin{tabular}{|c|c|c|c|c|c|c|c|c|c|c|c|}
\hline $\mathrm{DH} 36$ & $E / \mathrm{GPa}$ & $v$ & $\sigma_{y} / \mathrm{MPa}$ & $Q$ & $b$ & $C_{1} / \mathrm{MPa}$ & $\gamma_{2}$ & $C_{1} / \mathrm{MPa}$ & $\gamma_{2}$ & $C_{1} / \mathrm{MPa}$ & $\gamma_{2}$ \\
\hline $\mathrm{BM}$ & 200 & 0.3 & 350 & -48.6 & 87.5 & 4360 & 16.4 & 38524 & 116 & 8000 & 40 \\
\hline $\mathrm{WM}$ & 200 & 0.3 & 400 & -102 & 14 & 8912 & 29.65 & 102300 & 400 & 8000 & 40 \\
\hline
\end{tabular}

The elastic domain is described by a typical von Mises yield criterion $f=0$, where $f$ is defined as;

$$
f=J\left(\sigma-\alpha_{1}-\alpha_{2}-\alpha_{3}\right)-R-\sigma_{y}
$$

where $\sigma_{y}$ is the yield strength of the material, $\sigma$ is the Cauchy stress tensor and $J$ is the von Mises equivalent stress defined as;

$$
J(\sigma)=\sqrt{\frac{3}{2} \sigma_{d}: \sigma_{d}}
$$

where $\sigma_{d}$ is the deviatoric stress tensor. The isotropic hardening $R$ and the kinematic hardening $\alpha_{i}$ are defined as below;

$$
\begin{aligned}
& R=b(Q-R) \dot{p} \\
& \dot{\alpha}_{1}=\frac{2}{3} C_{1} \dot{\varepsilon}_{p}-\gamma_{1} \dot{\alpha}_{1} \dot{p} \\
& \dot{\alpha}_{2}=\frac{2}{3} C_{2} \dot{\varepsilon}_{p}-\gamma_{2} \dot{\alpha}_{2} \dot{p} \\
& \dot{\alpha}_{3}=\frac{2}{3} C_{3} \dot{\varepsilon}_{p}-\gamma_{3} \dot{\alpha}_{3} \dot{p}
\end{aligned}
$$

where $\dot{p}$ is the rate of accumulated plasticity, $b, Q, C_{1}, C_{2}, C_{3}, \gamma_{1}, \gamma_{2}$ and $\gamma_{3}$ are material parameters. Strain-controlled fatigue tests were carried out to calibrate material parameters. Numerical minimisation technique between the Finite Element (FE) model response and the stable hysteresis obtained from experiments is used to calibrate the required parameters. The material parameters obtained for DH36 base material and weld material are shown in Table 1.

\subsection{Shakedown analysis}

The applied load on the component should be below the shakedown limit, to achieve elasticshakedown state. Above this limit, a continuous plastic flow develops or constantly repeats until the structure collapses due to low-cycle fatigue.

On a component under cyclic loading, the plastic strain increment at the end of each load cycle over a time interval $n T$ to $(n+1) T$ can be expressed as:

$$
\Delta \varepsilon_{i j}^{p}=\int_{n T}^{(n+1) T} \dot{\varepsilon}_{i j}^{p} \mathrm{~d} t
$$

After each load cycle, the total work done on a body with volume $V$ and generalised displacement $\Delta D$ can be determined as:

$$
\begin{gathered}
\int_{n T}^{(n+1) T} P \dot{D} d t=W^{e}+W^{p} \\
W^{e}=\int_{n T}^{(n+1) T} \mathrm{~d} t \int_{n T}^{(n+1) T} \sigma_{i j} \dot{\varepsilon}_{i j}^{e} \mathrm{~d} V
\end{gathered}
$$

$$
W^{p}=\int_{n T}^{(n+1) T} \mathrm{~d} t \int_{n T}^{(n+1) T} \sigma_{i j} \dot{\varepsilon}_{i j}^{p} \mathrm{~d} V
$$

where $P$ is the generalised load, $W^{e}$ and $W^{p}$ are the elastic and plastic work done respectively.

After a specific number of cycles, if $\dot{\varepsilon}_{i j}^{p}=0, W^{p}$ will be zero and upon unloading, the right-hand side of equation (8) vanishes and there will exist a time-independent residual stress field $\rho_{i j}$ depending on the initial plastic deformation. This suggests that the structural response is elastic and hence the lower bound theorem is satisfied. Hence it can be concluded that $W^{p}$ defined in equation (11) can be used as a shakedown criterion.

$$
W^{p}=\sum_{i=1}^{N} \int_{V} \sigma_{i j} \Delta \varepsilon_{i j}^{p} \mathrm{~d} V^{e}
$$

where $V^{e}$ is the volume of an element and $N$ is the number of elements in the area of region.

\section{Methodology}

\subsection{Numerical methods}

\subsubsection{Weld model}

Thermo-Mechanical analysis of multi-pass Gas Metal Arc welding of DH36 steel was performed in a sequentially coupled analysis. This study uses an equivalent static heat source in conjunction with the 'chunking' method explained in section III.15.4.5.3 of [13]. The model was initially developed on a rectangular plate with dimensions of $400 \times 140 \times 12.7 \mathrm{~mm}^{3}$. The rectangular numerical weld model was then cut to the dimension of a mechanical load model as shown in Fig.1 The cutting was simulated by FEA using the element removal technique.

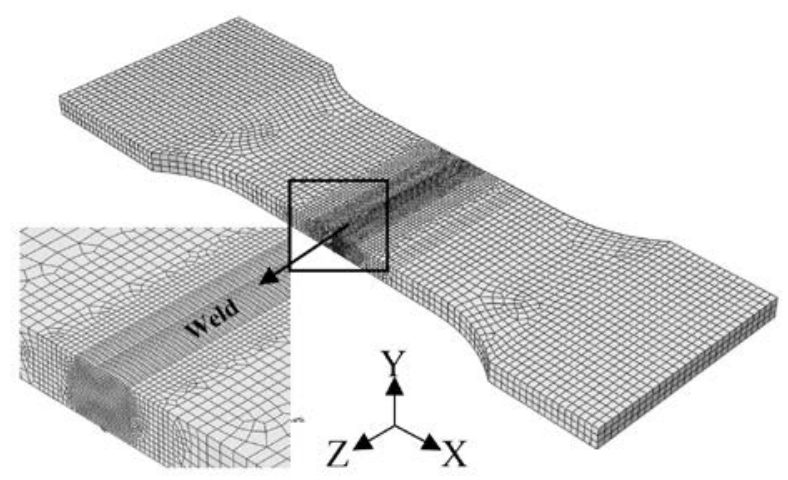

Fig. 1: Weld numerical model following element removal 


\subsubsection{Shakedown limit}

A numerical model was developed to estimate the shakedown limit of the butt weld at hand by considering plastic work done as the shakedown criterion. Consider a load domain $P$ defined as a region in the variable space which consists of load-time history. For $N$ independent generalised loads, $P_{1}, P_{2}, \ldots P_{N}$, the domain can be represented as

$$
P=\left[P_{1}, P_{2}, \ldots P_{N}\right]^{T}=\lambda\left\{\psi_{N} p_{N}\right\}
$$

where $\psi_{N}$ is the amplitude factor of $p_{N}$ which has an upper and lower limit and $\lambda$ is the generalised load factor. The objective of the limit analysis is to determine $\lambda$.

Initially, the shakedown limit of the butt-welded plate without weld residual stress was determined using a step-by-step iterative procedure illustrated in Fig.2. A Python script was used with the FE package Abaqus to implement the procedure.

Let $\lambda_{i}(i=1, \ldots \ldots . n)$ be load factors where $n$ is the number of increments. The largest value of $\lambda_{i}$ will be the load at which the structure can achieve shakedown with imposed boundary conditions. The procedure was implemented for uni-axial loading condition. The shakedown limit analysis was performed on a half model of the FE design used for the weld simulation.

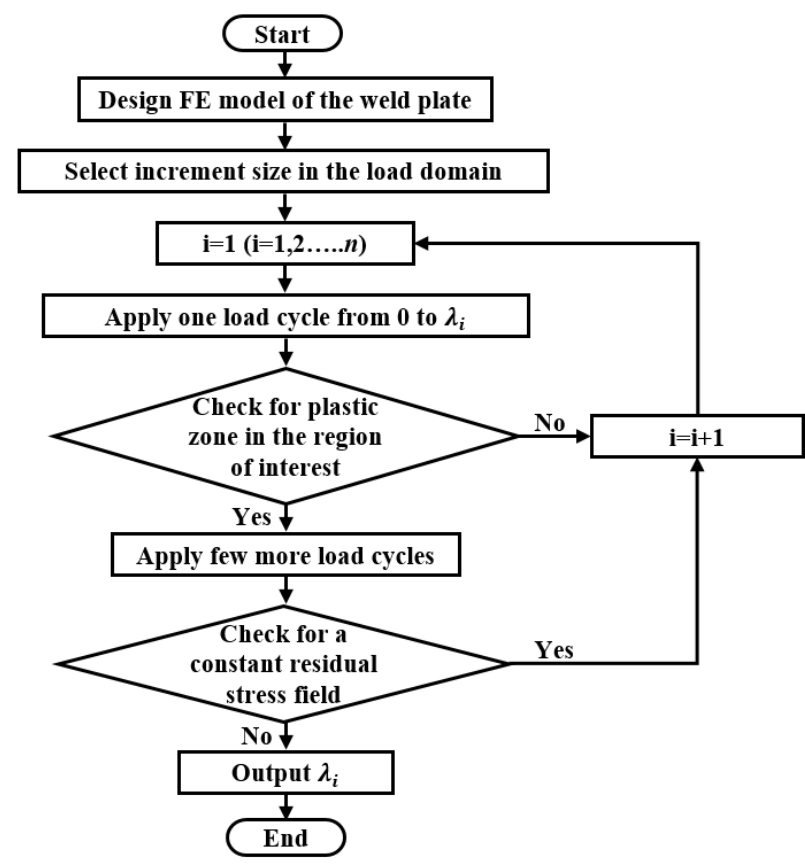

Fig. 2: Flow chart showing modelling procedure for shakedown limit analysis

An appropriate level of increment was selected according to the problem and the computational efficiency. The load variation used for the limit analysis is the same as explained in the next section. Initially, the structure is loaded from 0 to $\lambda_{i}$ and then unloaded, which constitutes a load cycle. The structure is investigated for any plastic zones developed following a single load cycle. If there exists a plastic zone, the structure is subjected to a few more load cycles until a stable residual stress field is obtained. If there is no plastic zone, then the load level is increased by an increment.

Stable residual stress is assessed by calculating plastic work done at each load step at a given $\lambda_{i}$. If the total plastic work of successive load cycles is equal, then change in plastic strain is zero and hence change in residual stress is zero.

\subsection{Experimental details}

\subsubsection{Specimen manufacturing and cyclic loading}

Gas Metal Arc Welding was employed to manufacture a weld plate of dimensions $400 \times 140 \times 12.7 \mathrm{~mm}^{3}$ with four passes with a procedure specification qualified in accordance with the Lloyd's Register classification. The plate was in full restraint during the welding process to represent welding in ship and offshore structures. Welding was performed along the width of the plate as shown in Fig. 3a. Thermocouples and high-temperature strain gauges were used to monitor transient heat and strain variations respectively. Thermocouples and strain gauge data were later used to validate heat transfer model in the sequentially coupled welding simulation.

Following welding, the weld plate was cut using EDM to prepare mechanical test specimens. After cutting, the plate was subjected to a few load cycles to study redistribution of weld residual stresses. Load cycles applied were tensile $(\mathrm{R}$-ratio $=0)$ half-sine cycles with $0.25 \mathrm{~Hz}$ frequency. The maximum applied stress used on each plate was equivalent to achieving $75 \%$ of the yield strength of the parent material $(350 \mathrm{MPa})$ to ensure that there is some residual stress redistribution. The load was applied across the weld and along the transverse residual stress component as shown in Fig.4.

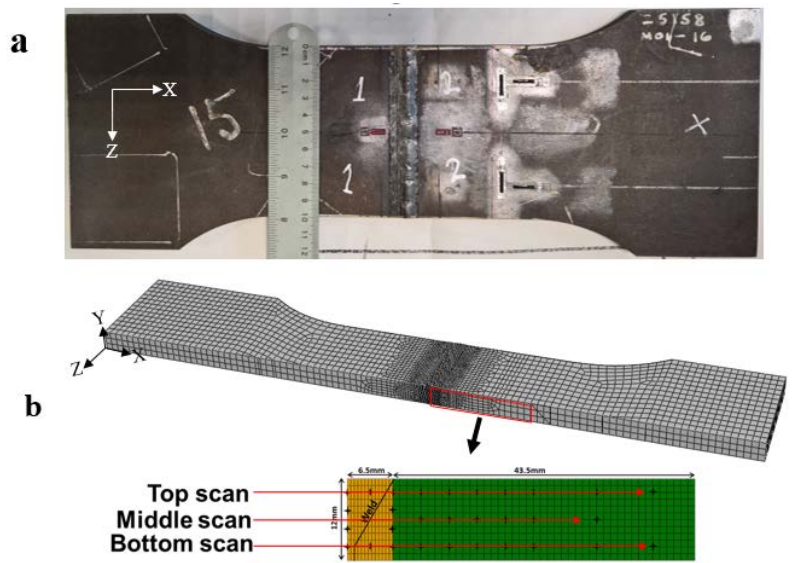

Fig. 3: a) Weld plate top view b) Front view of the measurement location

\subsubsection{Neutron Diffraction}

Neutron diffraction was used to measure residual stresses in the plates in the as-welded state and after different levels of shakedown. Neutron diffraction is a 
non-destructive technique which can determine strains through the thickness of a component. The ENGIN-X instrument at the UK's ISIS pulsed neutron source was used to measure the lattice spacing at each location using time-of-flight neutron diffraction technique.

The plate was set up in two different orientations to obtain all three principal stress components. With two detector banks at $\pm 90^{\circ}$ to the incident beam, it was possible to measure strains in two directions simultaneously. A gauge volume of $3 \times 3 \times 3 \mathrm{~mm}^{3}$ was used to obtain measurements from 30 points at midthickness across the weld and through the thickness at selected locations on the plate as shown in Fig. 3b. The measurements were performed in the as-welded state, after one load cycle and after three load cycles.

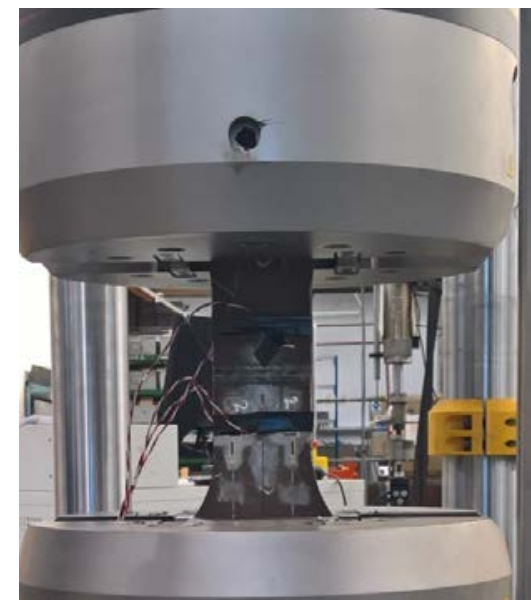

Fig. 4: The loading set-up

\section{Results and discussions}

\subsection{Shakedown limit}

A half of the weld plate is modelled for the limit analysis for computational efficiency. The FE model is subjected to increasing loads starting from $50 \%$ of yield strength of the parent material. The loading is gradually increased until a constant residual stress ceases to exist in the plate. After each load cycle, the equivalent plasticity at the end of a cycle is used to check the formation of plasticity. After about 40 many iterations, the shakedown limit $\lambda$ estimated by the FE model is 1.17. Now this implies that in the absence of residual stress field any cyclic load within 1.17 times the yield strength applied in this set-up will achieve elasticshakedown state.

\subsection{Residual stress redistribution}

\subsubsection{As welded residual stress}

Fig. 5 and 6 compare the numerically predicted longitudinal and transverse stress components and the neutron diffraction measurements in the as-welded state. The comparison is made across the weld taken from the top scan and bottom scan. Longitudinal stress components on and around the weld are as high as the yield strength of the corresponding material. The bottom scan of transverse component consisting of the root pass and near locations are slightly compressive. Less filler metal deposition and the low rate of cooling can be the reason for this. This distribution is consistent with plates welded with high restraint.

The numerical predictions have a similar trend with the measured values, and a good agreement was seen between the measured and numerically predicted values. However, the deviation in values may be due to the post machining performed on the weld plate before stress measurements along with the experimental errors and assumptions in the numerical simulations.

\subsubsection{Residual stress redistribution}

Fig. 7 and 8 compare the redistribution of longitudinal stress components from neutron diffraction measurements and numerical model after the application of three load cycles in the top scan and bottom scan respectively. As mentioned earlier, the applied load is along the transverse residual stress component, hence little relaxation on the longitudinal stress component is observed.

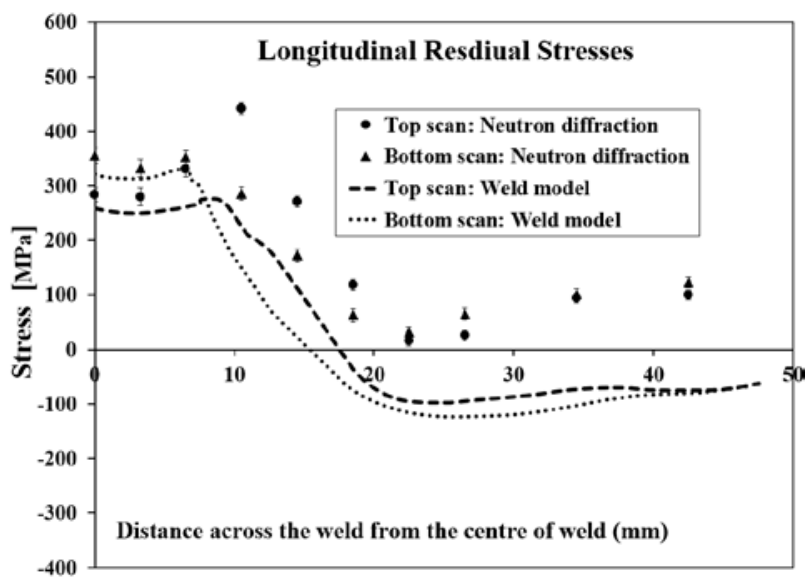

Fig. 5: As-welded longitudinal residual stress component comparison between experimental measurement and FE model

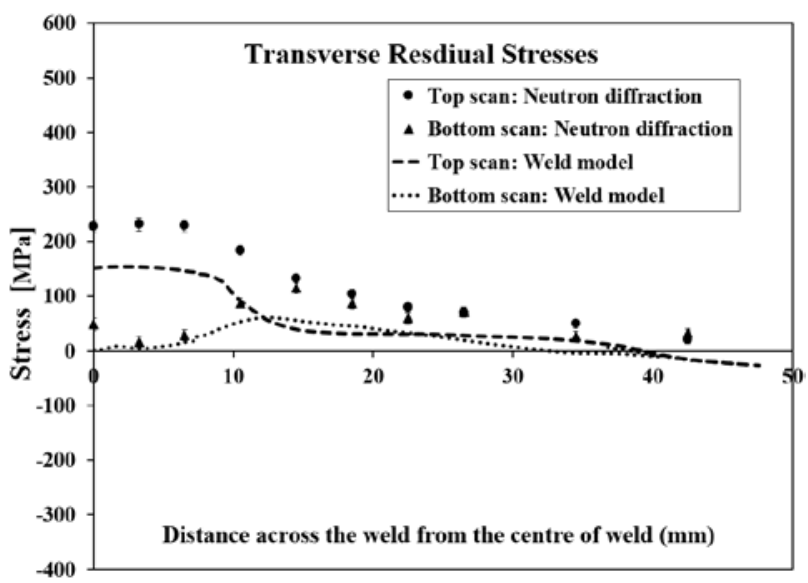

Fig. 6: As-welded transverse residual stress component comparison between experimental measurement and FE model 
0.7 times limit load was applied across the weld for the investigation of stress redistribution experimentally. The experimental results for all neutron diffraction measurements show that the redistribution in the longitudinal component is minimal for a load applied across the weld as shown in fig. 7 and 8. A slight relaxation of about $100 \mathrm{MPa}$ is noticed in the top scan near the weld toe moving away from the weld centre. The thickness and weld specification of the plate is selected based on the flat bar stiffener member in bottom deck of a ship structure. Since the capacity of the in-situ loading rig at ENGIN-X is not enough to introduce residual stress shakedown, loading was performed at TWI Ltd, between neutron measurements. Even though at most care was taken during the set-up, small errors are expected in consequence.

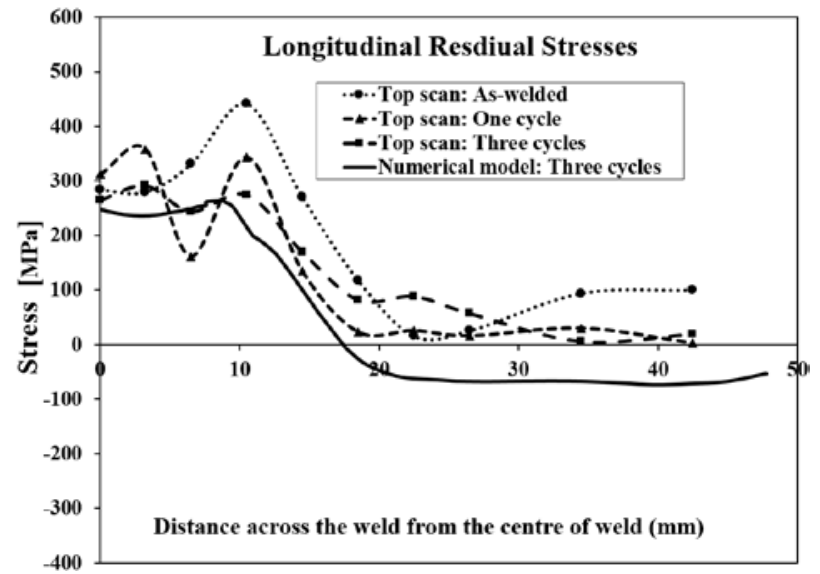

Fig. 7: Longitudinal residual stress redistribution in the top scan

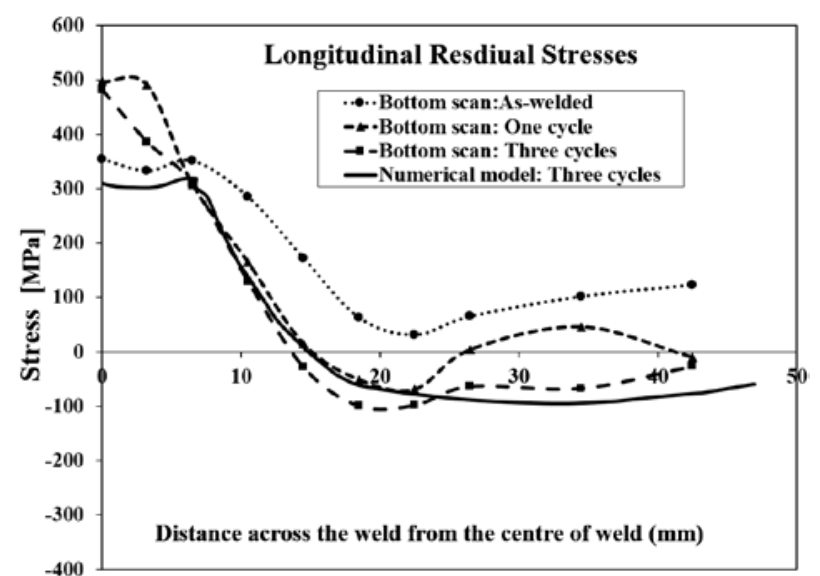

Fig. 8: Longitudinal residual stress redistribution in the bottom scan

Fig. 9 and 10 compare the redistribution of transverse stress components from experimental measurement and numerical model after the application of three load cycles in the top scan and bottom scan respectively.

Although the transverse residual stress following three load cycles shows redistribution, there are variations with which redistribution evolve in top scans and bottom scans. In the case of top scan, after three load cycles, experimental measurements show about 90\% relaxation, and numerical results show about $70 \%$ relaxation in the weld toe region. This can be attributed to the underprediction of initial weld residual stresses which is an influencing factor in the amount of relaxation. Percentage of relaxation after $N$ load cycles is calculated using equation (13). Additionally, the amount of redistribution is maximum after the first load cycle as shown in fig.9. This is in line with previous work in the literature.

$$
\mathrm{S}(\%)=\frac{\text { Initial } R S-R S \text { at Nth Cycle }}{\text { Initial weld stress }} \times 100
$$

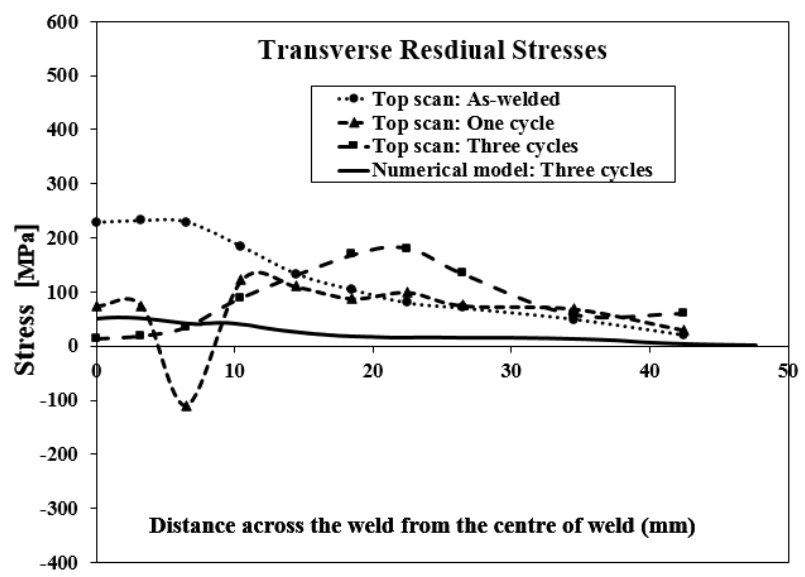

Fig. 9: Transverse residual stress redistribution in the top scan

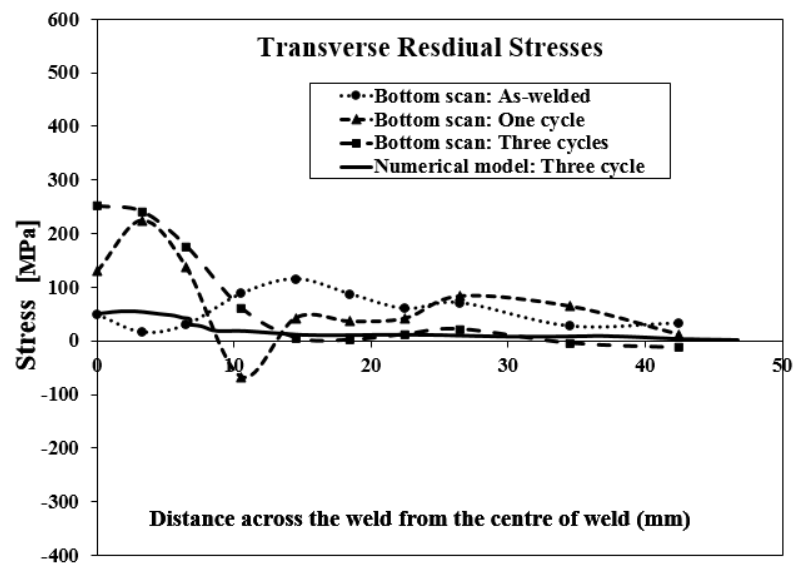

Fig. 10: Transverse residual stress redistribution in the bottom scan

On the other hand, the bottom scan of transverse component has moved more into the tensile zone than the as-welded state after the application of three load cycles. This small increase could be the variation of transverse component through the thickness to maintain internal equilibrium following relaxation in the top scan. The increase seen in the tensile stress in the neutron diffraction measurement is not seen in the bottom scan of the numerical model. However, there exists a tensile region with maximum stress of $90 \mathrm{MPa}$ at the midthickness following relaxation.

It is noted that preloading weld plates for relieving tensile stresses can be useful on the top surface or weld toe of the plate (which is considered as detrimental), but it can also introduce tensile stresses through the thickness. 


\subsubsection{Effect of shakedown}

A parametric study was performed in FE where the load cycles with magnitudes of $0.5,0.7$ and 0.8 times limit load were applied on the same plate with the same weld residual field. Fig. 11 shows the state of residual stress in the shakedown regime after the first three cycles. The shakedown region is defined by normalised applied stress and residual stress, both normalised by yield strength of the parent material.

With applied load levels at $0.5,0.7$ and $0.8 \lambda$, there is about 35,70 and $100 \%$ relaxation in transverse stress respectively in the weld toe region field after three load cycles. If the residual stress after first few cycles and the applied load is within the shakedown region it can be said that the structure will enter elastic-shakedown state and failure will be dominated by high cycle fatigue. Since the shakedown limit is calculated based on the same material model and the load variation, the evolution of accumulated plasticity will fall below the limit, given that there is adequate amount of relaxation in the first few cycles. It is defined as adequate relaxation because one should be careful in assuming shakedown state by just considering the relaxation in the initial residual stress. According to R5 procedure, for a structure to undergo shakedown state, it should have the maximum plastic zone developed in the section less than $20 \%$ of the section thickness [14]. If the applied load does not relax the stresses below the shakedown region in the first few cycles, it is likely to undergo reverse plasticity or ratcheting because of the accumulated plasticity over each load cycle.

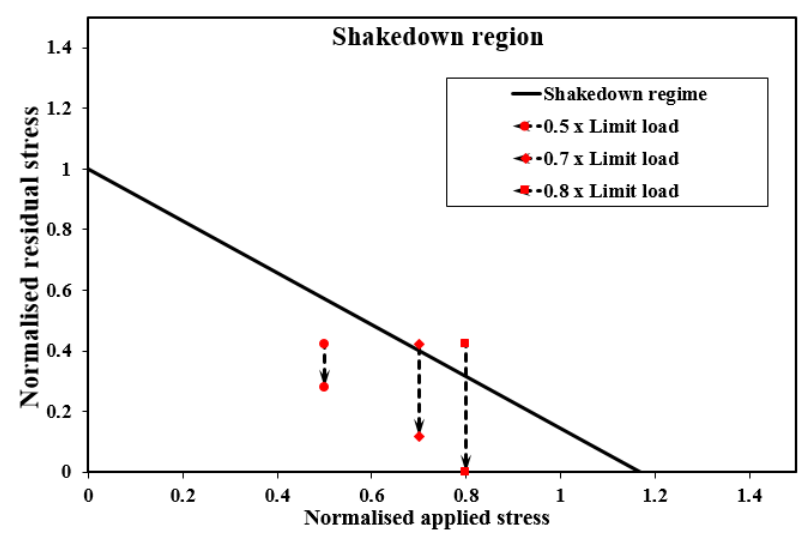

Fig. 11: Shakedown region after the first three load cycles

The authors are currently investigating the redistribution of residual stress on this plate after ten load cycles by experimental and numerical methods. Future study would be to investigate the effect of cyclic tensile loading on the longitudinal residual stresses in butt welds and on different weld joint configuration such as a $\mathrm{T}$-joint configuration.

\section{Conclusions}

In this work, the effects of residual stress redistribution on elastic shakedown and redistribution of residual stress at different applied load levels are discussed. The conclusions drawn from this study are:

- Shakedown limit of any component can be estimated using a simplified method where the change in plastic work done during each load cycle can be used as a shakedown criterion.

- Experimental measurement of residual stress redistribution after three load cycles of $70 \%$ limit load showed about $90 \%$ relaxation in transverse stress component at about $2 \mathrm{~mm}$ below the weld toe. However, $2.5 \mathrm{~mm}$ above the bottom surface shows an increase in tensile stresses near weld toe.

- In the presence of residual stresses, any component subjected to a cyclic load will achieve shakedown state if the combined applied stress and maximum residual stress after a few load cycles is below the shakedown region as shown in fig. 11.

Acknowledgements: - This publication was made possible by the sponsorship and support of Coventry University and Lloyd's Register Foundation, a charitable foundation helping protect life and property by supporting engineering-related education, public engagement, and the application of research. The work was enabled through, and undertaken at, the National Structural Integrity Research Centre (NSIRC), a postgraduate engineering facility for industry-led research into structural integrity established and managed by TWI through a network of both national and international Universities.

\section{References}

1. J. Eckerlid, A. Ulfvarson, Mar. Struct. 8: 385-406 (1995).

2. M. Abdel-Karim, Int. J. Pressure Vessels Piping 82: 427- 58 (2005).

3. J. Bree, The J. of Strain Analysis for Eng. Design 2: (1967).

4. E. Melan, Arch Appl Mech 9: 116-26 (1938).

5. W. T. Koiter, Proc. Koninkl. Ned. Akad. Wetenschap B59: (1956).

6. R5, 3rd ed. (2014).

7. J. Lemaitre, and J. Chaboche, Mechanics of Solid Materials, (1994).

8. T. Li, H. Chen, W. Chen, J. Ure, Int. J. Pressure Vessels Piping 88, 301- 10 (2011).

9. K. Yuan, Y. Sumi, Analysis and Design of Mar Struct, (2013).

10. Y. Huang, E. Stein, Eng. Fract. Mech. 54: 107-12 (1996).

11. B. C. Cerik, S. Cho, J. Mar. Sci. Technol. 18: 524-34 (2013).

12. Y. Sun, S. Shen, X. Xia, and Z. Xu, Mater Des 47: 106-14 (2013).

13. British Energy, R6 Revision 4: Assessment of the Integrity of Structures Containing Defects, (2014).

14. D. Knowles, Procedia Engineering 86, 315-26 (2014). 